\title{
APRENDIZAGEM BASEADA EM PROBLEMAS (ABP): PROPOSTA DE MODELO PEDAGÓGICO E AVALIAÇÃO DA EFETIVIDADE NA EDUCAÇÃO PROFISSIONA̧L
}

\author{
Luan Matheus Moreira, Thiago Inácio Barros Lopes \\ Instituto Federal de Educação, Ciência e Tecnologia de Mato Grosso do Sul - IFMS, Brasil \\ DOI: 10.15628/rbept.2019.7963
}

Artigo submetido em nov/2018 e aceito em abr/2019

\section{RESUMO}

O objetivo deste trabalho é de investigar a efetividade de um modelo pedagógico voltado ao aprendizado individual do estudante, incorporando-se a ABP, na unidade curricular de "Resistência dos Materiais 1", do Curso Técnico em Edificações do Instituto Federal de Educação, Ciência e Tecnologia de Mato Grosso do Sul - campus Aquidauana. Observou-se que $94 \%$ dos estudantes concordam que a "aprendizagem baseada em problemas" deve ser utilizada em outras unidades curriculares do curso, $87 \%$ dos estudantes concordam que a "aprendizagem baseada em problemas" despertou maior interesse pelas aulas e contribuiu para seu aprendizado e $88 \%$ dos estudantes concordam que a "aprendizagem baseada em problemas" proporcionou o desenvolvimento de habilidades como proatividade, criatividade e visão crítica.

Palavras-Chave: Metodologias ativas. Ensino. Aprendizagem.

\section{PROBLEM-BASED LEARNING (PBL): PEDAGOGICAL MODEL PROPOSAL AND EVALUATION OF EFFECTIVENESS IN PROFESSIONAL EDUCATION}

\begin{abstract}
The objective of this paper is to investigate the effectiveness of a pedagogical model aimed at the individual learning of the student, incorporating the $\mathrm{PBL}$, in the curricular unit of "Resistance of Materials 1", of the Buildings Technical Course of the Federal Institute of Education, Science and Technology of Mato Grosso do Sul - Aquidauana campus. It was noted that $94 \%$ of students agreed that "problem-based learning" should be used in other curricular units of the course, $87 \%$ of students agreed that " problem-based learning " aroused greater interest in classes and contributed to their learning and $88 \%$ of students agreed that " problem-based learning " have provided the development of skills such as proactivity, creativity, and critical insight.
\end{abstract}

Keywords: Active methodologies. Teaching. Learning. 


\section{INTRODUÇÃO}

As metodologias de ensino centradas no professor tendem a inibir o protagonismo do estudante e, consequentemente, minimizam os incentivos para o aprendizado do indivíduo. Logo, se o objetivo no processo de ensino e aprendizagem é propiciar a autonomia e o desenvolvimento integral do estudante, o docente deve utilizar metodologias de ensino que busquem este fim.

De acordo com Oliveira (2008), o individualismo metodológico implica na ideia de que, apesar das análises sociológicas tratarem de fenômenos coletivos, o indivíduo é o ponto de partida para a análise dos fenômenos sociais. Desta forma, conceitos coletivos como grupos, nações e estados não agem ou não existem no mundo físico; eles são apenas instituições criadas pelo homem e são utilizadas para descrever as ações similares ou conjuntas de indivíduos. Assim, se a intenção é adotar metodologias de ensino centradas no estudante, o indivíduo deve ser o ponto de partida para a análise pedagógica.

Segundo Berbel (2011), as metodologias ativas têm o potencial de despertar a curiosidade, à medida que os estudantes se inserem na teorização e constroem novos elementos - ainda não considerados nas aulas ou na própria perspectiva do professor. Quando acatadas e analisadas as contribuições dos estudantes, são estimulados os sentimentos de engajamento, percepção de competência e de pertencimento; consequentemente, os estudantes desenvolvem uma maior persistência nos estudos.

Pode-se compreender que as metodologias ativas se baseiam em mecanismos de desenvolver o processo de aprender, utilizando experiências reais ou simuladas, com o intuito de propiciar as condições de solucionar desafios advindos das atividades essenciais da prática social, em diferentes contextos.

O engajamento do estudante em relação a novas aprendizagens, pela compreensão, pela escolha e pelo interesse, é condição essencial para ampliar suas possibilidades de exercer a liberdade e a autonomia na tomada de decisões em diferentes momentos do processo que vivencia, preparandose para a atuação profissional no futuro. Desta forma, deverá contar com uma postura pedagógica de seus professores com características contrárias daquelas de controle, coerção e autoridade.

Barbosa e Moura (2013) resgatam que a ideia de trabalhar com problemas como meio para ensinar e aprender é bem antiga, pois já é conhecida a história do filósofo Confúcio (500 a.C.), que só instruía seus 
seguidores na resposta a algum problema ou questão após terem feito algum esforço próprio na busca da solução.

De acordo com Araújo (2009), a Aprendizagem Baseada em Problemas (ABP) - ou Problem-Based Learning (PBL) - surgiu na década de 1960 no Canadá, onde foi aplicada inicialmente em escolas de Medicina. Apesar da aplicação inicial na área médica, a ABP tem sido utilizada em várias outras áreas do conhecimento, como: administração, arquitetura, ciências da computação, ciências sociais, economia, engenharias e matemática. No Brasil, essa metodologia é aplicada regularmente em algumas instituições de ensino. É o caso da Escola de Artes, Ciências e Humanidades da Universidade de São Paulo - EACH/USP, onde a ABP foi incluída no currículo de dez cursos de graduação como método-base das disciplinas Resolução de Problemas desde 2005.

Esse método de ensino fundamenta-se no uso contextualizado de uma situação problema para o aprendizado autodirigido. Enquanto que nos métodos convencionais o objetivo é a transmissão do conhecimento centrada no professor, em conteúdos disciplinares, na ABP, o aprendizado passa a ser centrado no estudante, que deixa de ser um receptor passivo da informação para ser agente ativo por seu aprendizado. Logo, o professor atua como orientador ou facilitador nos grupos de trabalho ou estudo, nos quais a interação entre professor-estudante é muito mais intensa do que em aulas puramente expositivas (BARBOSA e MOURA, 2013).

Frequentemente, as situações problema utilizadas na ABP ocorrem por meio de trabalhos em grupo (LEON e ONÓFRIO, 2015), onde o estudante vivencia a experiência de resolução de um problema em conjunto com seus pares de modo a desenvolver saberes, habilidades e competências.

Neste momento, o intuito é explorar a ABP através de uma heurística alternativa: as situações problema serão submetidas aos alunos individualmente, porém, com a possibilidade de resolução em grupo. Desta forma, pode-se verificar se os incentivos para cooperação entre os estudantes serão potencializados, pois, devido ao desafio individualizado, o auto interesse (i. e., resolver o problema) e a interdependência (i. e., possibilidade de resolução em grupo) - que são características inerentes às relações humanas - podem ser os mecanismo desencadeadores desta suposta otimização do aprendizado.

Assim, o objetivo deste trabalho é de investigar a efetividade de um modelo pedagógico voltado ao aprendizado individual do estudante, incorporando-se a ABP, na unidade curricular de "Resistência dos Materiais 1", do Curso Técnico em Edificações do Instituto Federal de Educação, Ciência e Tecnologia de Mato Grosso do Sul - campus Aquidauana.

\section{METODOLOGIA}


A ABP será incluída em um processo cíclico, no qual o intuito é propiciar a aprendizagem significativa dos estudantes. Desta forma, em cada encontro, efetuam-se as seguintes etapas:

i. Breve exposição teórica contextualizada e dialogada: etapa dedicada à introdução dos conceitos teóricos planejados para o encontro, partindo-se de um problema a ser resolvido. Espera-se que o docente utilize o problema como meio para estimulação da curiosidade e criatividade dos estudantes;

ii. Proposição do problema: etapa dedicada à proposição de um problema mais complexo aos estudantes, de forma individual (i. e., cada aluno recebe um problema com dados de entrada diferentes), porém, com possibilidade de resolução em grupo. Na Figura 1 demonstra-se um exemplo de situação problema aplicada.

Figura 1 - Exemplo de situação problema

De acordo com a figura abaixo, calcule as reações de apoio dos pilares devido às ações atuantes na viga.

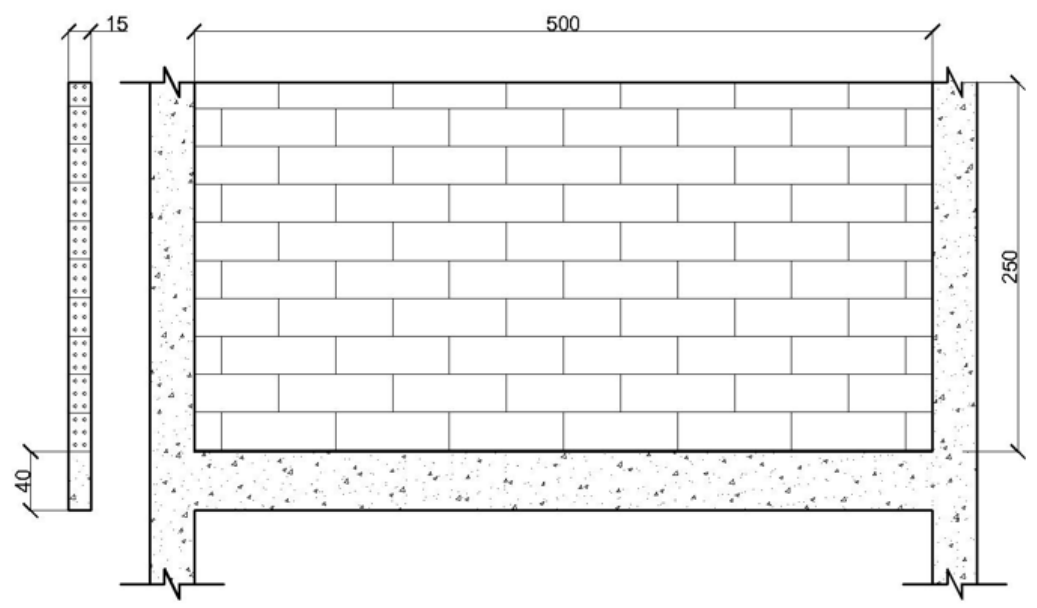

SUGESTÕES:

$\rho_{\text {alvenaria cerâmica }}=13 \mathrm{kN} / \mathrm{m}^{3} \quad \rho_{\text {concreto armado }}=25 \mathrm{kN} / \mathrm{m}^{3}$

Fonte: elaborado pelo autor

iii. Avaliação docente/discente: etapa dedicada a uma análise conjunta entre docente e estudante, de forma particularizada. Ou seja, ambos avaliam a solução proposta pelo estudante de modo a verificar possíveis equívocos quanto à resolução do problema. Trata-se de um momento de diagnóstico do aprendizado do 
estudante e, devido à circunstância construída, pode-se realizar a recuperação do aprendizado, submetendo o estudante a uma análise autocrítica e reflexiva.

Para avaliar a efetividade do modelo pedagógico proposto, construiuse um questionário que visa minimizar possíveis vieses de confirmação por parte do pesquisador. Deste modo, como os dados são coletados a partir da subjetividade dos estudantes (i. e., em sua dimensão integral: aspectos de aceitação, motivacional e funcional), a avaliação da pesquisa estará de acordo com os pressupostos teóricos (i. e., individualismo metodológico e ensino centrado no estudante). O questionário está definido no Quadro 1.

Quadro 1 - Questões analisadas sobre a contribuição da metodologia de ensino proposta

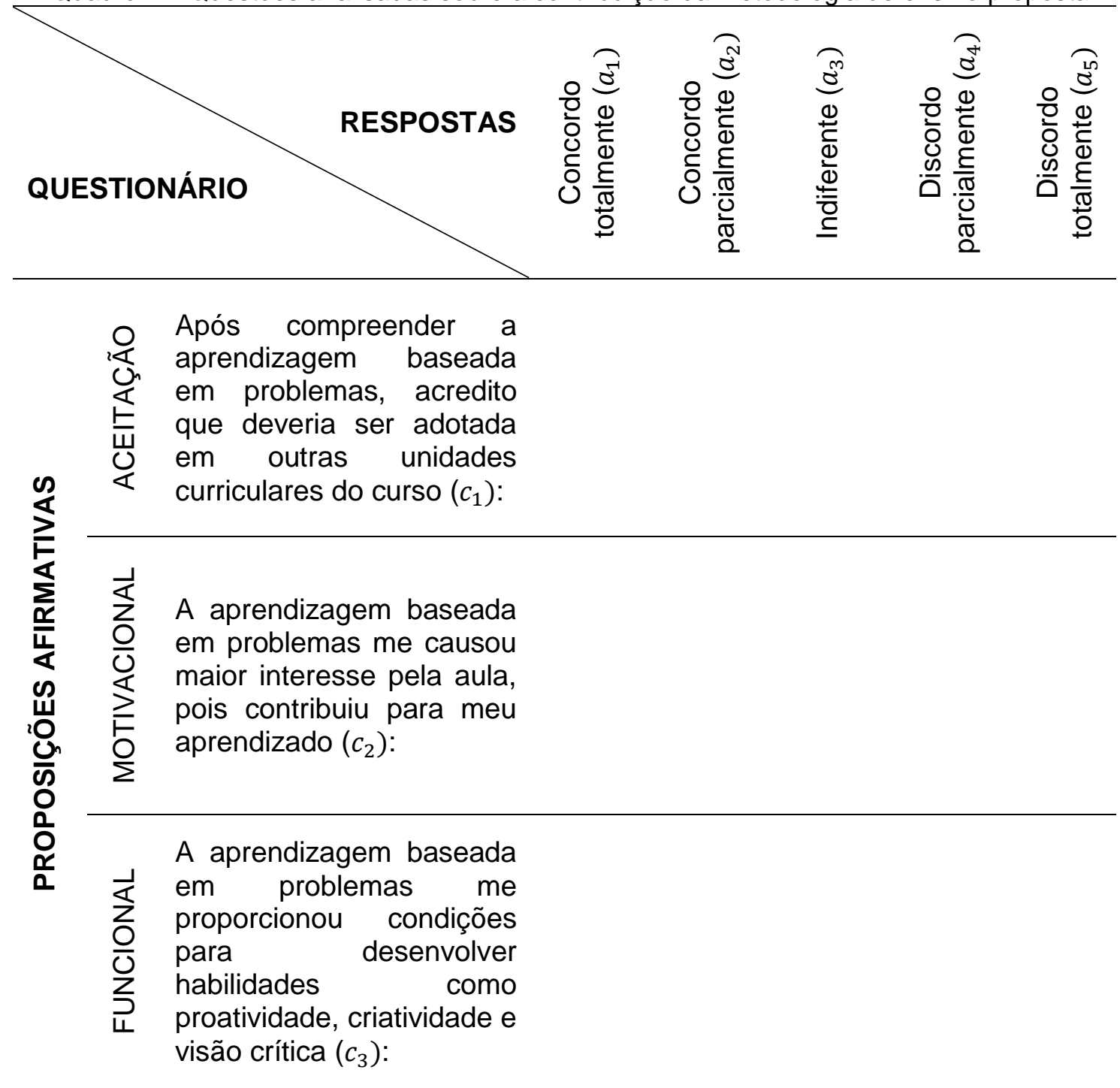

Fonte: adaptada de Bressane, Ribeiro e Medeiros (2017) 
A partir dos resultados do questionário foi utilizado um índice de contribuição da prática pedagógica para a formação integral, adapatado de Bressane et. al. (2017). O cálculo do índice - denominado E - foi realizado de acordo com as Equações 1 e 2.

$$
E=\frac{1}{3} \sum_{j=1}^{3} c_{j}
$$

Onde:

$c_{1}=$ componente de aceitação;

$c_{2}=$ componente motivacional;

$c_{3}=$ componente funcional.

$$
c_{j}=\frac{1}{5} \sum_{i=1}^{5} w_{i j} \cdot a_{i}
$$

Onde:

$w_{i}=$ proporção de respostas equivalentes a $a_{i}$;

$a_{i}=$ valor da alternativa $(i=1,2,3,4 e 5)$. Sendo $a_{i}=[1,0.75,0.5,0.25,0]$.

Assim, por meio dos cálculos das equações, o índice $E$ resulta em valores no intervalo [0 - 1], que podem ser interpretados como o grau de contribuição da metodologia de ensino utilizada para a formação integral dos estudantes, conforme proposto no Quadro 2.

Quadro 2 - Classes de interpretação para o índice E

\begin{tabular}{cc}
\hline $\mathbf{E}$ & Contribuição para a formação integral \\
\hline$<0,15$ & Muito baixa \\
\hline$[0,15-0,3[$ & Baixa \\
\hline$[0,30-0,45[$ & Média baixa \\
\hline$[0,45-0,55[$ & Média \\
\hline$[0,55-0,70[$ & Média alta \\
\hline$[0,70-0,85[$ & Alta \\
\hline$\geq 0,85$ & Muito alta \\
\hline
\end{tabular}

Fonte: Bressane et. al. (2017) 


\section{RESULTADOS E DISCUSSÕES}

O modelo pedagógico proposto foi experimentado com uma turma do $5^{0}$ período do curso técnico em edificações do Instituto Federal de Educação, Ciência e Tecnologia de Mato Grosso do Sul - IFMS. O grupo de análise foi composto por 28 estudantes ao longo de 8 semanas, no primeiro semestre de 2018.

No início das aulas, o plano de ensino foi apresentado para discussão, reflexão e possíveis mudanças em conjunto com os estudantes. Neste momento, também foi exposta a metodologia de ensino proposta neste trabalho, onde foi explicado o funcionamento dos "ciclos ABP" e suas respectivas etapas: breve exposição teórica contextualizada e dialogada, proposição do problema e avaliação docente/discente. Com isso, sabendo-se os conteúdos programáticos a serem trabalhados em cada ciclo, os alunos tiveram a possibilidade de antecipar os estudos e os possíveis questionamentos.

Os encontros semanais ocorreram nas quintas-feiras das $13 \mathrm{~h} 00$ as 17h00. Deste modo, cada ciclo ABP foi realizado em cada encontro, totalizando 8 ciclos. Ao término destes, aplicou-se o questionário do Quadro 1 aos estudantes e os respectivos resultados estão descritos nas Figuras 2, 3 e 4.

Figura 2 - Proposição afirmativa referente ao aspecto de "aceitação"

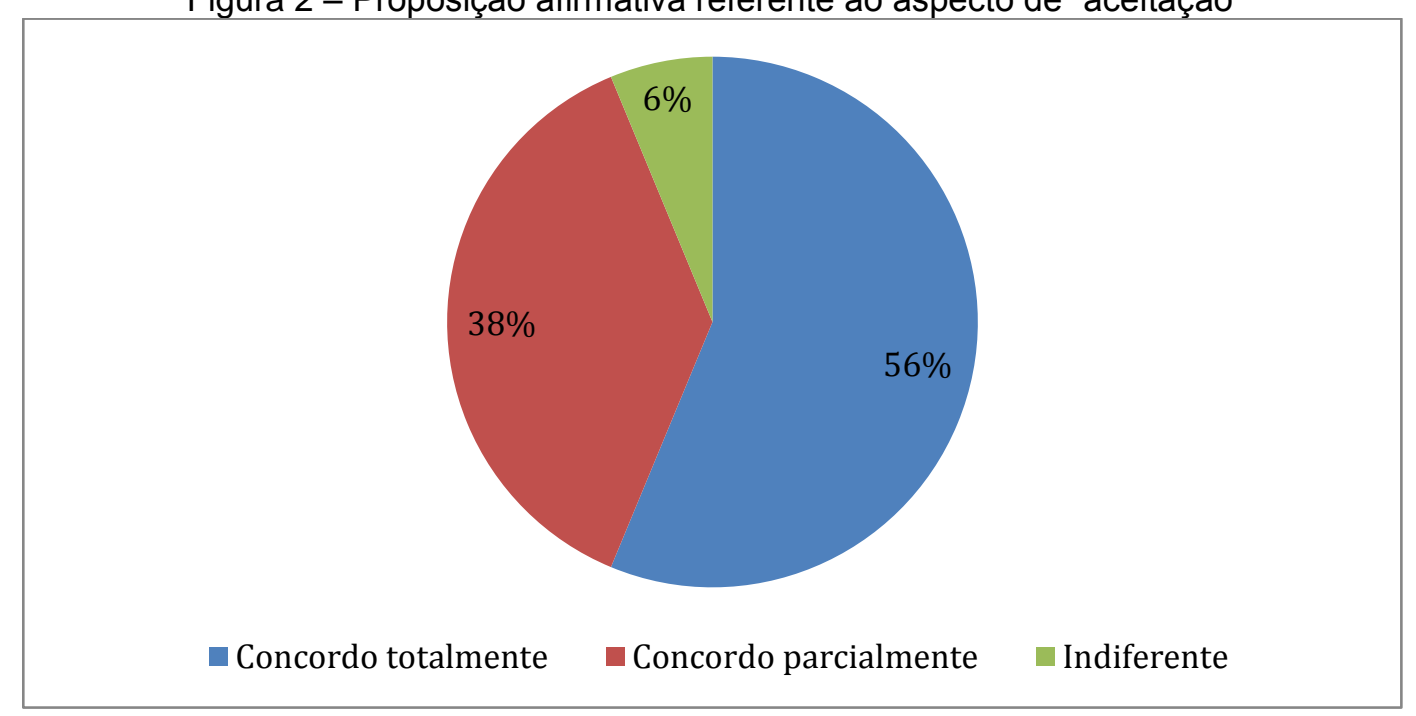

Fonte: elaborado pelo autor 
Na Figura 2 observa-se que 94\% dos estudantes recomendam que a "aprendizagem baseada em problemas" deve ser utilizada em outras unidades curriculares do curso, demonstrando-se um possível descontentamento com as práticas pedagógicas utilizadas nas demais unidades curriculares e/ou devido a dinâmica de teoria/prática que ocorre neste modelo pedagógico que, consequentemente, retira o estudante de um estado passivo (e. g., aula expositiva) e o coloca em um estado ativo no processo de ensino e aprendizagem.

Figura 3 - Proposição afirmativa referente ao aspecto "motivacional"

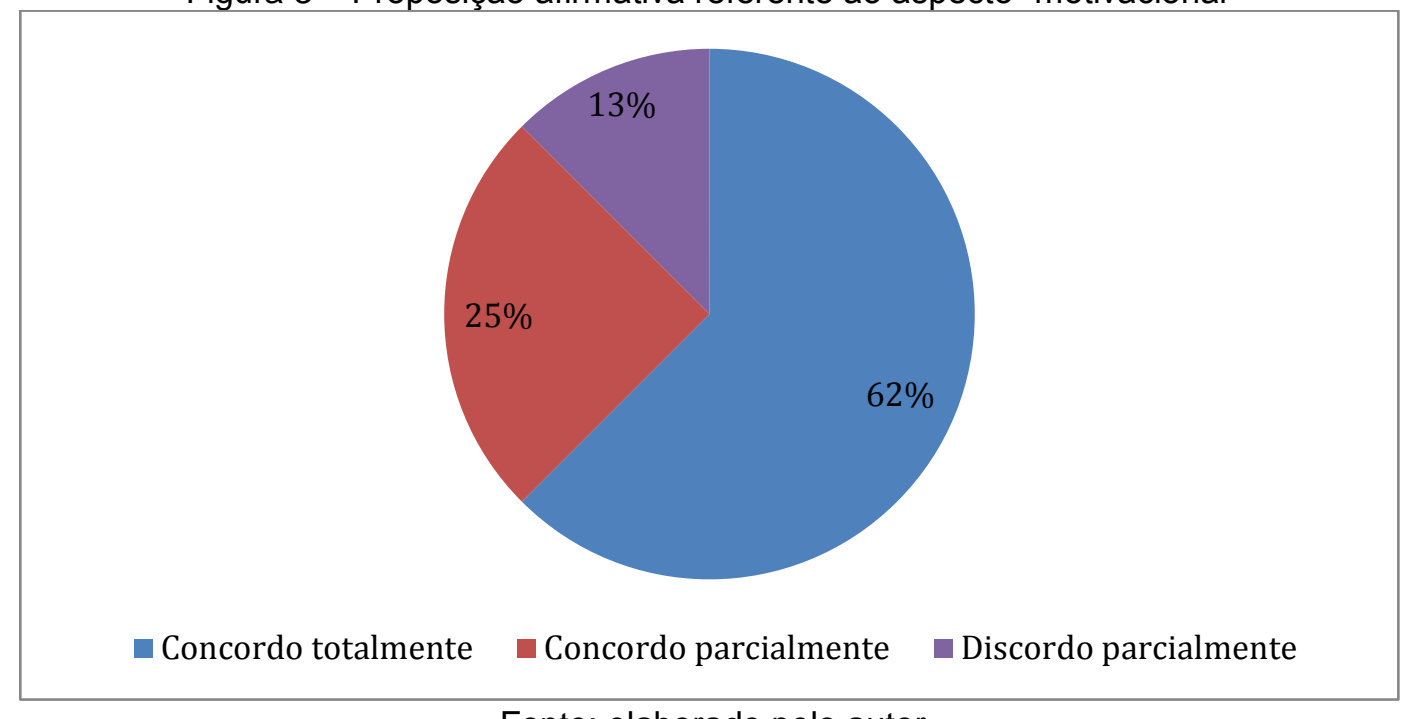

Fonte: elaborado pelo autor

Na Figura 3 observa-se que $87 \%$ dos estudantes concordam que a "aprendizagem baseada em problemas" despertou maior interesse pelas aulas e contribuiu para seu aprendizado. Isso corrobora com as hipóteses expostas na introdução e, consequentemente, propicia mais subsídios para a consolidação teórica do modelo proposto. No entanto, $13 \%$ dos estudantes discordam parcialmente disso, o que demonstra a necessidade do acompanhamento e da avaliação individual de cada estudante, de modo a construir, em conjunto com o mesmo, um ambiente para o processo de ensino e aprendizagem mais inclusivo. 
Figura 4 - Proposição afirmativa referente ao aspecto "funcional"

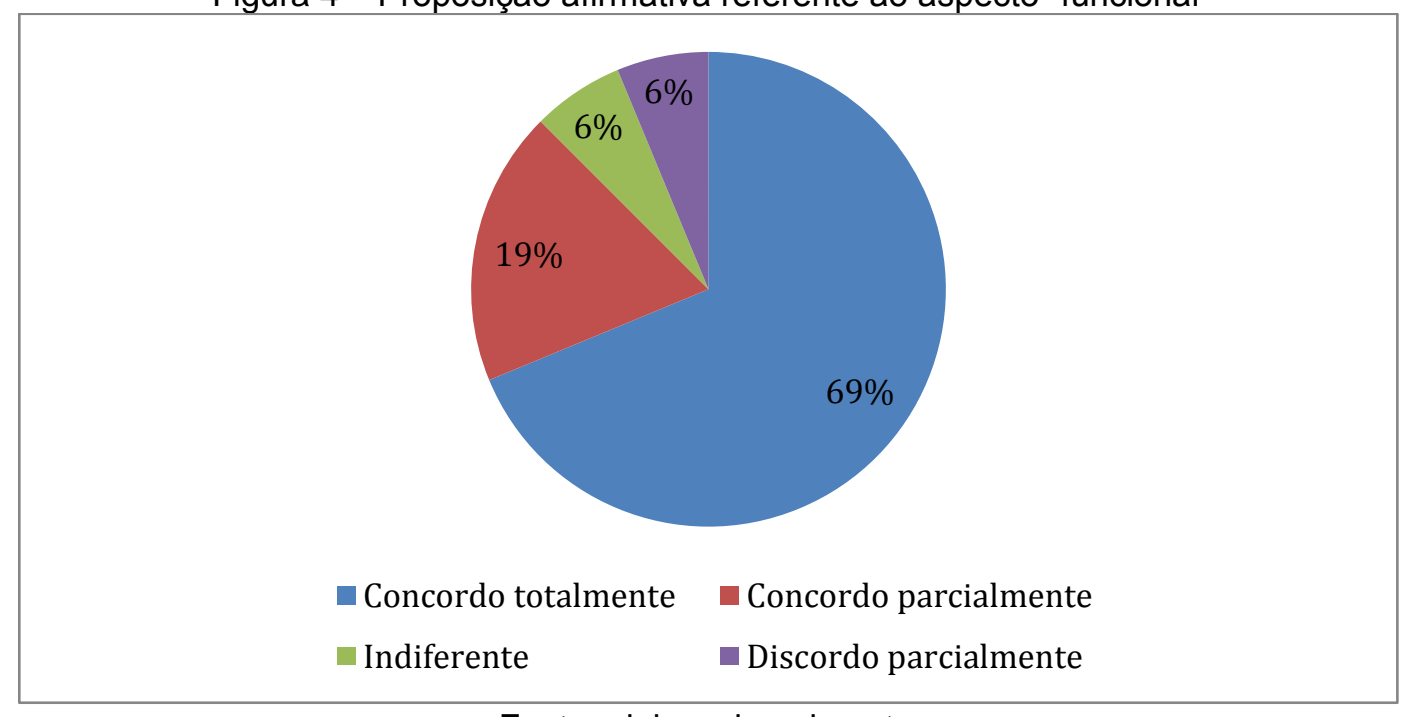

Fonte: elaborado pelo autor

Na Figura 4 observa-se que $88 \%$ dos estudantes concordam que a "aprendizagem baseada em problemas" proporcionou o desenvolvimento de habilidades como proatividade, criatividade e visão crítica. Enquanto que 6\% discordam parcialmente disso. Logo, pode-se afirmar que o modelo pedagógico contribuiu para a formação de habilidade socioemocionais, porém, assim como mencionado anteriormente, necessita de uma abordagem mais individualizada por parte do docente, de modo a buscar a formação integral de todos os estudantes.

Quanto ao índice de contribuição da prática pedagógica para a formação integral (E), a análise integrada dos componentes avaliados em cada questão (i. e., aceitação, motivacional e funcional), a partir das Equações 1 e 2 , resultou em um valor de $E \cong 0,86$. Com isso, de acordo com o Quadro 2, o nível de contribuição da metodologia investigada para a formação integral dos estudantes é classificada como "muito alta".

\section{CONSIDERAÇÕES FINAIS}

Atualmente, a aprendizagem baseada em problemas (ABP) é amplamente investigada e as evidências de sua contribuição para 0 aprendizado dos estudantes é conhecida. Neste trabalho, procurou-se idealizar um modelo pedagógico que agregasse valor à $\mathrm{ABP}$, incentivando-se o autointeresse e a interdependência dos estudantes.

De acordo com os resultados obtidos, pode-se concluir que o modelo pedagógico proposto se demonstrou efetivo para o processo de ensino e 
aprendizagem dos estudantes que participaram da pesquisa, pois os aspectos de aceitação, funcional e motivacional foram bem avaliados pelo grupo de alunos, resultando em uma classificação denominada "muito alta" em relação à formação integral dos estudantes.

A partir disto, pretende-se continuar o processo de aperfeiçoamento do modelo pedagógico, utilizando-se outras metodologias ativas (e. g., ABProjetos, Sala Invertida etc.), com o intuito de diversificar e otimizar o processo de formação integral dos estudantes.

\section{REFERÊNCIAS}

ARAÚJO, U. F. Aprendizagem baseada em problemas no ensino superior. São Paulo: Summus, 2009.

BARBOSA, E. F.; MOURA, D. G. Metodologias ativas de aprendizagem na educação profissional e tecnológica. Boletim Técnico do Senac, Rio de Janeiro, v. 39, n. 2, p. 48-67, maio/agosto. 2013.

BERBEL, N. A. N. As metodologias ativas e a promoção da autonomia de estudantes. Semina: Ciência Sociais e Humanas, Londrina, v. 32, n. 1, p. 25-40, 2011.

BRESSANE, A. et. al. Aprendizagem baseada em dinâmicas: uma proposta pedagógica para formação integral na engenharia. Revista de Ensino de Engenharia, v. 38, n. 1, p. 58-71, 2017.

BRESSANE, A.; RIBEIRO, A. I.; MEDEIROS, G. A. Simulação de consultoria como estratégia de ensino na graduação em engenharia ambiental. In: SOARES, S. R.; MARTINS, E. S.; MIRANDA, D. L. (Org.). Série Praxis e Docência Universitária. v. 6. Salvador: DUFOP, 2017.

LEON, L. B.; ONÓFRIO, F. Q. Aprendizagem baseada em problemas na graduação médica - Uma revisão da literatura atual. Revista Brasileira de Educação Médica, Rio de Janeiro, v. 39, n. 4, outubro/novembro. 2015.

OLIVEIRA, C. M. Metodologia e sociologia em Weber: alguns conceitos fundamentais. Revista Eletrônica Inter-Legere, n. 3, 2008 